\title{
Women in the Steel Industry: Closed in Corners or Provided with Possibilities'
}

I Minna Salminen-Karlsson ${ }^{2}$

Assistant professor, Centre for Gender Research, Uppsala University, Sweden

\begin{abstract}
The steel industry has been one of the basic industries in both Sweden and Finland. It is in a process of change, where research and development play an increasingly prominent role. In Sweden in particular, there is also an ambition to increase the number of women in the industry. This study is based on interviews and workshops with 12 women working in researcher or managerial positions in the Swedish steel industry. Their experiences show that employing more women in the industry is not enough to make effective use of the female talent pool, nor to increase gender equality. Besides belonging to a gender minority, women often had different backgrounds and career paths from their male colleagues, and their organizations need to be able to recognize the value of untraditional characteristics. The organizational environment determined whether these women became just an improvement in gender statistics or real gains in the quest for competence.
\end{abstract}

\section{KEYWORDS}

Career / gender / inclusion / organization and management / steel industry / Sweden

\section{Introduction: Swedish steel industry in a process of change}

teel industry in Sweden is one of the 'basic industries', and has traditionally been an important actor in the economy on which the welfare state was built. Today, it is international, but still largely Nordic, and steel plants in Sweden are owned by both Swedish and Finnish companies. The industry is in a process of change. The number of employees decreases, even if not dramatically: in 2008, the best year in the 2000's, the industry employed 35000 people, compared to 28,500 people in 2017. This means that the steel industry employs about 5.3\% of all employed people in Sweden (SCB 2019). Research and development have become more and more important, as the industry is finding its future in highly specialized products rather than just refining Swedish iron ore. The industry is constantly looking for a highly qualified workforce, including in research and development. This also means that the traditional steel worker masculinities are complemented with more middle-class engineering masculinities. The process is reminiscent of the one described by Abrahamsson and Johansson (2006) regarding the development of masculinities in Swedish mining: earlier, a 'macho-masculinity' with valorization of physical strength and physical work prevailed and was guarded by a refusal of being associated with anything feminine. However, with increasing technologization, more and more mining work has become a matter of remote controlling, which forces miners to develop new worker identities and new masculinities.

\footnotetext{
${ }^{1}$ You can find this text and its DOI at https://tidsskrift.dk/njwls/index.

${ }^{2}$ Corresponding author: Minna.Salminen@gender.uu.se.
} 
The percentage of women in the Swedish steel industry has remained almost the same, having gone up only from 18\% to 19\% between 2008 and 2017 (SCB 2019). Hence, male domination prevails in steel industry.

Steel plants are often located in small or medium-sized towns, and have been the main employer in a town, creating a particular gender and class order. Today, such local gender contracts are changing (Stenbacka et al. 2017). However, long traditions are not easily changed, and the process of transforming social relations in the steel industry does not happen overnight. The women who come to the industry as engineers and researchers can meet very different organizational cultures and gender power orders depending on where in the industry they work.

This study was initiated by the realization that the steel industry is in constant need of new expertise, and has actively engaged in recruiting a female workforce, with meagre success. The original aim of the study was to find out how women who work with highly qualified technical work in this traditional male dominated industry are received and create their careers in the organizations. This was done by listening to the women's stories about their careers. It was during this listening and primary analysis that the more focused research question emerged: What is the difference between work contexts in steel companies where highly qualified women's expertise is taken up and those where women find themselves in marginalized positions?

\section{Background: Women in male-dominated industries}

\section{Women as a business case}

The situation in the steel industry is succinctly described by Johansson and Ringblom (2017), even if their findings are based on two other Swedish traditional and maledominated industries: forestry and mining. Just like steel industry, these industries face societal demands to be more gender equal - which is generally interpreted as referring to the numerical gender composition of the workforce and also at managerial levels. Just like mining and forestry, the steel industry also adheres to the discourse of women being a business case, that is, the expectation that the industry will be much better, because the working environment will improve and productivity and innovativity will increase with an increased numerical gender balance. Johansson and Ringblom identify several problematic features in this reasoning: gender equality measures are directed to attracting women, rather than changing the basic gender orders in the workplaces. The focus on improving the numbers also places more focus on the women who are not in the industry than on the women who are already there. Further, the focus on attracting women makes gender issues consensual, something that most people can agree on, instead of introducing potentially contested issues of gender and power.

\section{Tokens, power, and possibilities}

Kanter's (1977) work showed that the differences between men's and women's organizational behavior largely depend on their positions in the organization. The best known of these is the 'token' position of minority women that Kanter was the first to describe. 
However, being a token is only one of the aspects that she pointed out as the context that influences the behavior of members in organizations. She also referred to opportunities and power, and stated that the possibilities that an individual perceives regarding her advancement and development in an organization are important for her behavior: if opportunities seem to be open, an engagement for the organization and efforts to advance appear, but if opportunities seem to be closed, the individual becomes disengaged, less eager to perform and more prone to leaving the organization. In this way, the opportunity structures in organizations become decisive for improving the numerical gender balance, in particular in managerial positions. They also easily create positive or negative spirals, in that in companies where women's opportunities are limited, they more easily accept subordinate roles or leave the organization, while in companies where women are promoted, more women are interested in managerial positions.

Kanter's third aspect, power structure, has been elaborated by a host of researchers after her (Acker 1990; Alvesson 1998; Ridgeway \& Smith-Lovin 1999; Fletcher 1999; Halford \& Leonard 2001; Ely \& Padavic 2007), and men's and women's differential access to power has been confirmed by their studies. Large industries are often hierarchical, and access to power comes by climbing corporate ladders. In many traditionally organized companies, the support of people at higher levels in the organization is crucial for advancement, having contacts through networks is important, and the attitude of single individuals in key positions matters (Dwivedi et al. 2018). In industries where managerial positions are staffed in more structured ways, women's numbers in management increase (Reskin \& McBrier 2000).

Amis et al. (2020) see Kanter's (1977) findings as applicable to current organizations, and how they reproduce inequalities. While the token concept has been the most widely used from Kanter's work, Amis et al. also refer to her theorizing of homosociality in recruitment, organizational cultures, hierarchies, and the socialization of new members in organizations (to perceive themselves as being on a career path, or as not being capable to assume leadership positions). Amis et al.'s conclusion is that organizations still have issues in all these aspects, and that this hampers organizational diversity and consequently organizational efficiency, as minority members will lower their aspirations and, hence, not strive for performing their best.

While Kanter's (1977) results have been confirmed, over and over again, her interpretation of them has also been contested. For Kanter, the minority status, not gender, was the issue causing problems. Watkins et al. (2019), in their review of 87 articles, only look at the concept of tokenism, and confirm that it is not gender neutral, but that, with a few exceptions, being a token is disadvantageous for women but may be advantageous for men.

Lewis and Simpson (2012) refer to research that uses Kanter's concepts and agree that what Kanter thought of as basically gender-neutral dominance relations, actually mirror gender power relations in society. Lewis and Simpson read Kanter's description of the organization she studied with a post-structural, Foucauldian understanding of power and highlight the invisibility of the normalcy of the male majority as something that is absent in Kanter's reasoning. Lewis and Simpson refer to later research that validates the observations Kanter made as still relevant, but they see Kanter's interpretations in terms of power struggles concerning invisible masculine norms in an organization. They do not discuss women's careers as much as these masculine norms, and how women may either 'disappear' as women by adapting to the norms, or reveal the norms, 
choosing to use their exposed situation as token women. What Kanter defines as visibility, Lewis and Simpson discuss in the framework of the masculine gaze, which may not only accept and possibly co-opt the woman but also push her away from the organization, physically or mentally, or render her invisible.

Ever since Kanter's theorizing about tokens, the need for women to take on masculine characteristics to compete successfully in male-dominated organizations has been described and discussed by researchers on gender and organizations (Miller 2004; Demaiter \& Adams 2009; Powell et al. 2009; Derks et al. 2011; Kark et al. 2012, Einarsdottir et al. 2018; Baublyte et al. 2019). However, there is also research that nuances this image: societal gender dynamics as well as organizational dynamics change over the years, and expectations towards managers become more relaxed, allowing for greater variation including in gendered behaviors (Muhr 2011; Johansson et al. 2019). The importance of a particular organizational context is seldom elaborated in these studies. Research generally shows that, in spite of increased degrees of freedom, women experience a need for adaptation to fit into male-dominated professional contexts. However, individual companies can show large differences in what is informally required from their female members.

\section{Four strategies for being a woman in a male-dominated organization}

Kvande (1999) interviewed a large number of Norwegian women in engineering, and found that they could be sorted into four categories: 'homeless', 'one-of-the boys', 'compensators' and 'challengers'. These are not identity traits, but possible ways of acting in the engineering environment. Accordingly, a woman as a person cannot be categorized into one of the boxes, but may use different strategies in different contexts and during different phases of her life. Kvande bases her categorization on the extent to which the women saw themselves as similar to or different from their male colleagues, and how important they thought an engineering career was for them. The 'one-of-the-boys' and the 'homeless' both build on an idea of sameness: generally, women and men are seen as similar, and 'oneof-the-boys' women try to gain access and positions by using the same measures as they see their male colleagues use. The 'homeless' often have not quite found their position in the profession or in the organization, or have been assigned and have accepted a position where they do not compete with their male colleagues any more. However, they still do not think that their trajectory is due to their gender. The 'compensator' and 'challenger' strategies are based on an idea of gender difference. The compensators accept that they as women are outsiders in the male-dominated engineering company, and shift much of their interest to the private sphere. The challengers perceive themselves to be in a particular position because of their gender, but they challenge the gender order in different ways.

Kvande's (1999) categories take the women's organizational contexts into account, in that the 'homeless' strategy appears where the organization does not provide opportunities to its female staff, and the 'challenger' strategy requires an organizational context with at least some openings for working towards gender equality. Harman and Sealy (2017) also arrived at four different categories of strategies when they studied young women's career ambitions in one large male-dominated organization, but they tied these strategies more tightly both to the single women's backgrounds and to the organizational context. Their two parameters are self-efficacy and organizational context: high self-efficacy and positive organizational context promote strong ambition and 
a successful career, while high self-efficacy and negative organizational context may lead to leaving the organization, unless the woman can find a particular expert role that satisfies her ambition. A positive organizational context is not enough for a woman with low self-efficacy to strive for managerial positions, as she still will have low ambition and limited career progress. Low self-efficacy and negative organizational context will lead to either leaving the organization or to leaving it mentally, maybe adopting Kvande's 'compensator' strategy. Harman and Sealy thus confirm Kanter's (1977) basic assertion that if women do not see opportunity structures, they are likely to leave the organization. However, they nuance Kanter's observations about minority status being the reason for women's stalled careers; Kanter expected that women as well as men were willing to climb the corporate ladder, and would have done so if their minority status and lack of power and opportunities had not put obstacles in their way. However, Harman and Sealy found that many of their interviewees were not even interested in a corporate career, as they felt that leadership tasks or the way to get there required that they would become a kind of person they did not want to be.

Harman and Sealy's (2017) main point is that women's ambition to pursue careers is shaped both by internal factors, their ambition based on their upbringing and schooling, that they carry with them into the organization, and by external factors, how they are received and treated in the organization. To maintain one's ambition and thrive in the organization, male managers and mentors, recognition, and support from partners at home are important.

Carvalho et al. (2018), writing 40 years after Kanter (1977), find that in recent research obstacles to women's careers are often seen as structural, while successes are attributed to individual women. In their study of managers in the tourism industry, they point out that opportunity structures, as described by Kanter, can be both positive and negative, and neither successful nor stalled careers can be attributed to individuals or structures only, but always emerge in an interplay.

Kvande's (1999) 'challengers' and Harman and Sealy's (2017) women in a positive organizational context and with high self-efficacy, show how positive opportunity structures can facilitate women's careers, but, in general, the research on whether current work organizations also have positive opportunity structures for women, is much scarcer than research on obstacles. However, Holgersson and Romani's (2020) study of a Nordic IT company contradicts Kanter's (1977) findings about the negative effects of tokenism for female senior consultants. They found that token women were not hampered in their career ambitions and had considerable agency in moving the company towards greater gender equality. While Holgersson and\& Romani do not suggest that Kanter's findings might be outdated in today's organizations, they conclude that organizational culture can strongly modify them.

\section{Methods}

This study started as an action research project in collaboration with an organization connecting several steel companies in Sweden. The participants were recruited by our contact person in that organization. In the first phase, she contacted a number of steel companies to find women who would be interested in participating in a series of four workshops discussing gender issues in the steel industry. Altogether 16 women participated in at 
least one of the workshops, which took place in the period March-November 2017. The workshops were audiotaped, but not transcribed verbatim. However, extensive notes, including direct quotes, were written down on basis of the recordings.

All the women participating in the workshops who were willing and available were individually interviewed. This amounted to nine women. In addition, our contact person recommended three more interviewees, who were in high positions in steel companies. Altogether 12 women were interviewed. Their ages ranged from 30 to 66 years, with the average of 47 years, and their experiences in the steel industry were between 2 and 29 years, with an average of 9 years. All but one of the women had children, most of them more than one.

Six of the women had completed PhDs, one had a licentiate, one a MSc, and one was working on her $\mathrm{PhD}$. Not all the women were employed by a steel company: one of them was our contact person in the steel industry organization (2 years), another one worked with a research institute in close collaboration with several steel companies (with a background of 2 years in a steel company and 18 years in this position), and a third one was a consultant working with the local steel industry (5 years). In addition, one interviewee was formally employed by a university, working on a $\mathrm{PhD}$ financed by a steel company and spending a lot of time at the company. All the women not attached to a steel company participated in the workshops, that is, they were motivated to share experiences to improve gender equality in the steel industry. Four of the eight women employed by a steel company had leadership positions.

Three of the women were interviewed face-to-face and the remaining nine by phone, because of the geographical distances. Both kinds of interviews followed the same pattern, and we found that, as Holt (2010) argues, phone interviews are a satisfactory alternative to interviewing face-to-face, even if the interaction can be somewhat more disrupted due to the lack of physical cues.

In addition, three men in one organization, where one of our female interviewees worked, were interviewed. One of them had 18 years' experience in the steel industry, while the other two had 5 years' experience each. All of them had been in managerial positions. These interviews were made by phone. The interviews dealt with gender issues in the steel industry in general. While a sample of three cannot give a comprehensive image of how gender is perceived and discussed among male managers in steel industry, these three interviews exemplify gender discourses that exist in the industry.

The interviews lasted on average around one hour. All interviews, including the phone interviews, were recorded and transcribed verbatim. All interviews were conducted in Swedish and the quotes in the article are translated by the author.

The interviews dealt with the interviewees' life history and professional history, and their hopes and plans for the future. These interviews were part of a larger, inter-Nordic research project, and the interview guide was aligned with other guides in the project. A general inspiration in the project was feminist life history research (Stanley 1992), even though the interviews with the women in steel industry did not cover their whole life but concentrated on their professional history, with the starting point in the present.

All the material was coded inductively. After that, each interview was read separately asking what the interviewees said they did not get, have or do, based on Husu's (2005) statement that for women in the academic sphere the main problem, rather than outright discrimination, are the things that do not happen to them but do happen to their male colleagues. During this reading, the interviews fell into three groups: women

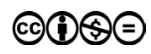


who were dissatisfied with their situation (5), women who were happy about their situation (5), and two women who could not be categorized that way, even if one of them was closer to the satisfied and the other closer to the dissatisfied group. The two groups were then analyzed separately to examine their experiences in their work organizations. Coded material from the workshops was used to supplement interviews, when appropriate. As the terms 'satisfied' and 'dissatisfied' refer to individual feelings, they were replaced by the terms 'marginalised' and 'included', when the analysis showed that the women's (dis)satisfaction was, while individual, largely caused by the opportunity structures in the companies where they worked.

\section{Findings}

\section{Three examples of gender equality discourses in the steel industry}

The differences between the contexts where the women worked can be illustrated by the three men who were interviewed for the study. As the total sample is only three people, there are no claims of representativeness. Rather, the three men are seen as representatives of three different gender discourses in the steel industry, each of them potentially influencing women's career options, though in different ways. They are an illustration of the differences between work environments in an industry in a process of change, by examining the attitudes of managers who largely create the work environments.

Anders was conservative in a way that is quite uncommon in Swedish official discourse. According to him, men were not favored in the industry and at the workplaces masculine jargon only appeared as an exception. Instead, the reason for the low percentage of women in the steel industry was their unsuitability for that kind of work. Having women in the steel industry, including in research and development, caused lots of problems, according to Anders. Not only did women have to take parental leave for a long time, they also became sick more often, and had burnouts.

The women we have had, I can see that they've been very ambitious, but then they may not have been able to prioritise it right, and they, they've had a burnout. There you can see a small difference compared to men, who do that part a little, a little more relaxed, so to say, and also try to prioritise their job in another way and do not become too stressed if run short of time and can't do it all.

Women were problematic in the work environment, as they tended to feel stressed or harassed or be in conflicts much more than men. They were also problematic, as the presence of women in the workplace made it difficult for the men to talk in a natural way: 'I have often experienced that women are a bit more sensitive, you cannot say everything you want to and so'.

A woman getting Anders as her manager would probably not have great career prospects, unless she could use the one-of-the-boys strategy exceptionally well.

Eric had, to a large extent, adopted the current discourse about the need for women in the steel industry. Several times during the interview, he referred to recruiting women and making them visible as a task imposed from outside the industry, from collaborators, for example. 
As always, when we organize conferences and so, we try to find clever women who fit in, because we want to be, have diversity. [...] But it's not always so easy. For example when we worked with this conference I told you about, to get as equal a distribution as possible, but there are very few women and very many men, so it becomes, we had a workshop in March here, and there we also had some, not so many presentations, but of course it was two men presenting there, so we got zero points for that.

The main problem, according to Eric, is the scarcity of women in the area. According to him, the work to get more women into the industry has to start very early, during the early school years. Since Eric defined gender equality problems as dealing with numbers, which were determined by individual women's choices of education and industry, he had difficulties in answering the question about what the industry could do to advance gender equality: 'A good question. Well, I think, it's about ... I don't think you can do anything revolutionary, I think you should, no, I don't know, I can't find the words right now'.

A woman getting Eric as a manager seems to risk being the business case, improving the numbers and being showcased, but not getting any help in navigating the maledominated environment.

Fabian had a different approach. In his professional life, he had worked in organizations outside the steel industry, and also worked with and managed women. He had also had female managers himself. In contrast to Anders and Eric, he talked about structural and cultural issues such as men who take up space:

I have a feeling that women maybe have had to step back for all the men who have taken up more space. And it may be more like, you can't actually say that the man who takes up more space is more able to push the work forward than a woman who may not ... It's a little because, men are more, more, they swagger a bit more.

In relation to gender issues, Fabian also criticized the current authoritarian leadership ideals in the steel industry:

I have an idea that in the steel and mechanical industry they also choose managers who are tough, kind of. And maybe that's not needed all the time. Of course, women can also be tough, but generally they have a more modest approach to being a manager. More perceptive. [...] I think the idea of leadership needs to be changed a bit.

A woman getting Fabian as a manager, would probably be encouraged to take space and build up a career.

Words do not equal actions, but the way these managers, especially Eric and Fabian, discursively framed gender equality problems were echoed in the real-life experiences of the interviewed women.

\section{What has not happened to the women?}

Both included and marginalized women told that care obligations had not been a major obstacle for them. Most of them talked about caring for children as something that needed to be managed, but something that was manageable. Where the collaboration 
between the parents and the societal day care services did not suffice, grandparents or friends could step in. However, even if the women said it was possible to combine family and career, they did juggle the demands in their work and the demands that the environment placed on them as mothers, maybe in particular in a small-town environment.

Both included and marginalized women also told that they had not followed a traditional career path. Many of them said that their backgrounds were broader: instead of climbing the organizational hierarchy in one particular part of the company, they had collected experiences from a broader spectrum. The female managers had reached their present positions in companies which, in addition to being positive to female workforce, also could free themselves from the traditional career path model and see that nontraditional trajectories can be valuable as a management background.

However, there were also differences between the marginalized and included groups. The marginalized women told that they did not have support, they could not see a way forward in their organization, their competence was not acknowledged, and in general the company was not a place they wanted to work in. In contrast, the included women told that they had not applied for but had been offered managerial positions, that what they had to say was not dismissed and that they were not alone, but had female role models and networks. Especially the marginalized women told the same negative stories about being in a token position, that have been recorded in previous research on women in male-dominated industries (e.g., Bagilhole et al. 2002; Miller 2004; Watts 2007; Faulkner 2009a and b; Hatmaker 2013; Seron et al. 2018; Khilji \& Pumroy 2019). However, some included women told stories about being able to change things from their token position, comparable to the findings of Holgersson and Romani (2020).

\title{
Marginalized women in traditional companies
}

Inger who had changed companies a number of times during her long career told that she had observed the phenomenon of the glass ceiling in several companies, which were engaged in improving their gender quota:

\begin{abstract}
A young, enthusiastic woman comes in, often they've been through a trainee programme, so they are already identified as up and coming. And initially she gets formidable backing. Interesting tasks and she gets visibility both internally and externally, almost like she gets exploited, because she is always brought forward when the company needs to show how good we are at gender equality. So she gets lots of space. And she grows, it would be hard not to succeed with all this unbelievable backing. And in a way it's really good. But then she feels that now I'm ready for new, bigger challenges. And then there is compact resistance. Maybe she's told directly that she should be grateful, you can't always expect to only have fun tasks. And they make up totally impossible career paths, where you have to be team leader and project leader and specialist in parallel. Totally absurd situations. I've seen that a number of times.
\end{abstract}

Such experiences are a good illustration of problems when women are seen as the business case, that is, the number of women and, consequently, recruiting them is perceived as the core task and core problem when it comes to gender balance. Women are needed to improve statistics and to be shown up as representatives of the company's gender equality 
mindedness. The company presents itself as a good place for young women, which is not very costly either financially or organizationally - even if some of the woman's young male colleagues may feel that she gets too many favors. However, the situation becomes different when the woman starts to compete with her male colleagues for possibilities to climb the company ladder or lead bigger projects. Then, she is going to severely disrupt the structure where men have traditionally appointed their male followers.

Interviewees who were dissatisfied with their situation had often experienced some version of this trajectory, with initial promises, which were later withdrawn.

\title{
I do not have support anymore
}

Three of the five marginalized women told about having been deceived by the employment prospects originally offered to them. They were recruited by a male manager and along the way there may have been individual men who helped these women. However, a woman's situation depended on these individual men, and when the men moved or did not offer support anymore, the women found themselves stuck in an organizational niche. Malin explained how she felt cheated by the original offer:

\begin{abstract}
The guy who employed me said that it is quite clear that you should get to be a [position], and this is something that we will regulate. We don't employ anybody to that position, so the best I can do is to take you in at a lower position. When you become a [position] we often do a salary review that gives you a bit of an extra raise. As I reduced my salary when I started at [the company], he said that it was an advantage, because that will give us the possibility to regulate your salary up, so you get the same salary as you had before. I was naïve and believed it, and now I have understood that no, that will not happen.
\end{abstract}

The women, when trying to change their situation, may have been offered other positions that they were not interested in. When these women have started looking around, they have seen female colleagues who have also met with difficulties. They have seen that those women have got administrative positions, not working with technology anymore, or that they have left the organization.

\section{My competence is not acknowledged}

The lack of possibilities to advance was associated with being invisible as a professional. Women who work with research are highly specialized, and, in particular, if they have landed in units where their competence is not at the core, their managers may simply not understand what they are doing, as Malin explained, 'Now, after three years, I'm in a situation that my current boss, he says "I don't really understand what you do, and that is why I feel no engagement for you"'. Malin found it impossible to show her closest manager, and the manager above her, how her work benefits the company as a whole. The problem could be interpreted as being about new technology coming into old structures, where the value of the novelty is not understood. However, in the light of previous research on women's competence being devalued (Rudman et al. 2012; Joshi 2014), it is not unreasonable to assume that her gender plays a role: because of her gender Malin's 
'incomprehensible' work is marginalized instead of being cherished as new ideas that will benefit the company.

Women's competence may also be under-utilized because of internal competition in the company. Anna talked about being marginalized and finally pushed out, because her company had fierce internal competition. Ylva was experiencing something similar:

They are tiptoeing in my area. There was something we needed, that I thought I'd build. Now, my boss and another colleague have already started with that and they don't invite me to meetings, they make sure that they build it up themselves. Absolutely, it's a big difference. I don't think they have really tried to find out about my competence, either.

The companies may have employed the women, believing that the number of women is the business case. However, the women tell how their competences do not benefit their companies, because they are invisible or not used due to internal competition regarding positions and prestige among the male majority.

\section{I don't want to stay here}

Many of the marginalized women were looking for ways out of their work situation, while others had adopted the 'compensator' strategy, directing their focus on their lives outside work.

Malin was changing jobs at the time of the interview, after several years of trying to get promotion. She had been loyal to the organization, trying to improve her position, until she felt quite sure that it would not be possible. She talked enthusiastically about the warm welcome she had received in her new company. However, in a way she felt sorry for having to leave.

In this case they have offered me even more than I asked for, or even imagined in the beginning, because they think that it's reasonable [...] but at the same time there is some sorrow in it still, because I did not think that I would change jobs after four years.

For the marginalized women who are in a process of changing companies or who have already done so, it has taken time and a change of mindset to decide to leave a position, even when it has been uncomfortable.

Ylva had decided to change careers completely, and go outside the industry, after being in several positions and even self-employed in technology. She was not tired of steel, but of the workplace:

I would have liked to become a manager in the job I've now, for I think it would have suited me, you have to be communicative, you have to be broad, you don't need to be a specialist, you have to understand the technology, understand the context, which people need to be involved and so [...] They asked me to come down to the headquarters and I understand that they had this idea in the back of their heads, they asked me some things and I showed how I had thought about it but then [...] I said that I will leave. [...] The job is great, we have a great goal, great vision, [...], I can see what we could have done there, it is about the working climate and that I can't use my full potential. 
Ylva may have met the problem that can occur in hierarchical organizations: the highest level of the organization may have been positive about her and her competence, but the male group around and immediately above her had already made her feel so tired of the organization that she had taken steps to change her life. However, Ylva was the only person we interviewed or heard about in the interviews who had seriously thought of doing something completely different.

\section{Included women in progressive companies}

\section{I did not ask to become a manager}

The included women told almost completely different stories. While they did not say that their paths had been totally uncomplicated, they gave evidence of support that had facilitated their ambition, leading to work satisfaction and good careers (cf. Harman $\&$ Sealy 2017).

Three of the included women had leadership positions, two at quite a high level. They had not asked for them, but had been identified in the company and asked whether they were interested. They also told that this was quite common among other female managers they knew and explained that often the question came without the woman even having thought of such a possibility. And not only had they not thought of applying, sometimes they had actually been persuaded to take the next step in the company, like this woman who is a manager of quite a big unit:

I got a question once, 'Linda, this job is out, wouldn't it be something for you, in production?' And I said, 'no, it's not really me'. 'But think awhile about it, I believe it would be' the manager said. Two people said that to me, one was the HR manager and the other was my manager. And I said, OK, we can talk. And so it happened that I got in from an organization of 15 people working on [...], into an organization with a responsibility for 250 people. [...] And it was so much fun! And when I had had that job for a while, my manager at the time asked, 'Linda, would you not apply for this job.' And it was actually quite a long persuasion campaign, because I myself was quite hesitant. I still had quite small children, just started school. But finally I thought, okay, if they believe in me in this, okay.

Not only had these women not actively sought managerial positions, but they also talked about how they, and some of their female colleagues, had more or less actively avoided such positions. Fredrika still talked about her previous job as an expert as the best job in the world, and told that for several years she had declined offers of managerial jobs, until she had got one that she felt she could not refuse. She wants to stay in her present position, but when asked about her future plans, she says that she could also go back to her specialist work, far lower in hierarchy to the job she has now.

The hesitation before taking on high-level managerial jobs could be about women's insecurity about their own abilities, but, as in Fredrika's case, it could also be about enjoying their present tasks and therefore not being interested in climbing the ladder (cf. Harman \& Sealy 2017). For the companies, it not only meant that the female potential not only needed to be recognized and promoted, but also persuaded to take on highlevel positions. Kristina was satisfied with her situation even if she never had established 
herself as a manager. She was ambivalent, in that she both expressed a clear desire to become a manager and at the same time said that she probably would not be very good at it. She says that she is settled in her present situation as a researcher and enjoys it, saying no to job offers from other companies - even if she would happily take up a good managerial position in her present company if it was offered to her.

\section{I’m not ignored}

Contrary to the marginalized women who felt that their competence was not recognized, the included women told that they were listened to, just like the men in their working environments. Three of the included women explained how the desire to make a difference, to use power to direct things, was their motivation. When asked what she would do in 5 years, Fredrika was prepared to return to her specialist role, but she also enjoyed the possibility of using her experiences from that role to make decisions about the future:

I feel such an enormous power right now, to be part of this and do things in a way that I believe in. No, I haven't had time to think about it, but I do feel a power in my job right now. Now I'm in a position where I can be part of steering in a direction that I believe in. It feels good. [...] I have no illusion that I can push through all the ideas of how we should do things, that it would be completely implemented and work without any friction in less than five years, I have no illusion. So my agenda is already for five years, so I hope that I'm still in this position in five years.

The included women did not talk about push factors that would make them want to leave their companies. Some did talk about changing positions and companies as an option, and they also knew that it would not be hard for them to find a new job. However, the reason for changing would not be to get better positions or working conditions, but to try something else, not to stall in the current comfortable position.

\section{I'm not alone}

In addition to help from their managers, the included women talked about the importance of female networks. Women-only networks and courses can be accused of creating unnecessary boundaries between men and women, and they are not always seen as compatible with other gender equality policies (cf. Andersson \& Lidestav 2016). Inger, one of the more senior interviewees, had reflected on the issue, but thought that female networks had been crucial for her:

I have tried to explain to my boss, the best one of them all, because he said 'You can't have a problem, you think like we do, so what's the problem?' But in some way I had questions and I had thoughts that never really got through to my male colleagues.

Obviously, in some women's work environment, there existed a discourse of women being envious and not able to collaborate, and there were women who referred to such 
opinions and said that they really did not hold true. However, it was also acknowledged that some women actually did over-ride other women or resisted gender equality initiatives, because they had an individual competitor perspective and did not see structural gender issues. No such women were among those of our interviewees who were in high positions. Our interviewees talked about gender equality work they and their companies were doing. However, the conditions of doing these things varied between companies. While some senior women proudly spoke of their company policies or how they could influence them, more junior women provided narratives drawing attention to harassment and discrimination and meeting with resistance.

The senior and more powerful women seemed to exist in companies with good gender equality measures, relative to those where some of the junior women struggled. However, some senior women also talked about their junior years, and of wanting to play at being one of the boys and downplay their femininity. With age and the good career this had changed and they were now happy to be female role models and help younger women. Several of them had initiated or tried to initiate gender equality activities in their organizations. They had become 'challengers' in Kvande's (1999) terms, challenging the male norm of the organization. Having a possibility to partake in allfemale environments, and in particular all-female leadership courses, had been crucially important to raise awareness about the particular situation of being a career woman in a male-dominated industry.

\section{Discussion}

The process of change that the Swedish steel industry is in, is mirrored in these 12 women's experiences as highly educated female employees. This change is taking place in a society where gender equality is constantly advocated in different ways (Andersson 2018; Martinsson et al. 2017). When it comes to engaging more women in male-dominated areas, employing women is seen as a solution to a problem, a particular mission, different from just employing 'people as usual'. But as long as women are relatively few, Kanter's (1977) concept of tokenism is relevant for their situation. Just as described by Kanter, many of them are visible, they are stereotyped, they need to find ways of assimilating into a male-dominated cultures, and they are put to the test in terms of performance and loyalty.

The steel industry needs all the competent workforce it can get, and women are seen as part of the solution. Increasing the percentage of women is also seen as the right thing to do. However, because the right thing is defined as increasing the number of women, many companies do not see that more has to be done if they want to take advantage of these women's competence. The interviews with the three men illustrate different discursive approaches to gender issues: while Anders only superficially aligned with the gender discourse in the industry, Eric was interested in improving the numbers and Fabian in making it possible for women to show and use their competence. What happened to the women in the companies was largely determined by how the issue of gender equality was perceived (Bacchi 2009), whether the most important aspect was the number of women or their competence.

However, organizational aspects do not alone determine a career trajectory, as Harman and Sealy (2019) argue. An aspiration for leadership positions is seen as the 
default in research on gender and organizations, including Kvande (1999) and Harman and Sealy. However, not everybody, neither men nor women, aspires for advancement (Powell \& Butterfield 2013) - even if it mainly is women's disinterest that has attracted the attention of researchers. While it is difficult to know to what extent women's satisfaction is an unconscious adaptation to the perceived opportunity structure in the organization, the possibility that a career actually is not of importance in a woman's (or man's) life cannot be ruled out.

Common to all the female interviewees was the fact that they had been welcome in their companies to start with. For a newly graduated $\mathrm{PhD}$, this is a positive experience. In that position, it can be quite difficult to evaluate the future opportunities in the company, and it may rather be sheer luck if she gets into one of those companies that value women's contributions - or ill luck if she gets into a company where she gets trapped in an uncomfortable position.

Some companies employ qualified women and assume that these women will meld in with the company just like anybody else. However, if the structure and culture of the company are traditional and built on male hierarchies, Kanter's (1977) findings apply: women become both invisible as competent employees and visible and disturbing the traditions as women, being actively marginalized in different ways, and finding it difficult to find their way through the organization. Other companies have actively promoted women and these women, in turn, have encouraged other women. In both cases, there may have been a single male person in a good position who has initially encouraged the newly employed woman. However, in the companies where there were no organizational structures or cultures to support their efforts, they had come to nothing. In such companies, women considered opting out, but both loyalties and practical reasons - such as finding another job within commuting distance - made them ambivalent. Considering the good employment prospects of these women, the traditional steel industry may well benefit greatly from such hesitations and ambivalences.

The differences in gender equality policies and practices are large between the companies. None of the companies where the interviewed women had worked could eliminate the fact that women are a minority, often in a token position. It was how the companies dealt with these tokens that made the difference. The companies where women thrived were not described as less hierarchical than the others, so the explicit power structures were not the heart of the matter. However, organizational opportunity structures differed and could be either disadvantageous or advantageous for female employees and result in any of Kvande's (1977) coping strategies. In the companies where the number of women was seen as the business case, they were left to deal with their position on their own, and this promoted the strategies of becoming one-of-theboys or a compensator or staying homeless - and plans and actions for leaving the company. The companies where women thrived were not totally without fault - even the included women mentioned harassment or resistance - but yet, these companies had been supportive enough to enable these women to become challengers. These companies may also have initiated positive spirals in that the women could contribute to recruiting and retaining more female competence, for example, by acting as role models and mentors, or contributing to policy decisions. These companies defy the standard description of tokenism as harmful for women, and allow the token position to be invested with power (cf. Holgersson \& Romani 2020). It is hard to tell whether women in the companies where they are included get special attention, or whether they just 
enjoy the same advantages as men always have done, but it seems that for the companies where women are marginalized there is a long way to go: both to stop subtle and open discrimination and to encourage the women, to make it possible for them to use their potential.

The majority of the women interviewed in this study do not work on the factory floor - even if some have done so, and tell that the experience has been rather positive. Instead, they work in laboratories, representing the increasing technologization of the industry. This technologization itself may represent a threat to the traditional steel worker identity. The women who come into the industry, in general, have a higher education than their male colleagues: of women employed in steel companies, $25 \%$ have a higher education degree, while the corresponding percentage for men is $10 \%$ (SCB 2019). Hence, the women are not only newcomers because they are women, they also represent a transition that is desired and advocated, but can also be threatening for traditional masculine identities (Abrahamsson \& Johansson 2006). These masculine identities do not only exist on the factory floor: many managers in the steel industry have made their careers in the industry and are part of its collective identity. The negative experiences of the women may in part have their roots in this threat. The fact that women had a different background and often also a different trajectory in the organization could be seen as a problem or as an asset by the leadership, depending on their general attitude to change.

This analysis of the interviews has focused on the organizational aspects. Naturally, these interact with individual traits and characteristics, and there may have been intragroup commonalities in the life histories of the women in each group, which might partly explain the differences in their positions and their satisfaction with their working life at the time of the interview. However, the gendered opportunity structures in the workplace where an individual woman arrives largely determine her future professional life - and her contribution to the Swedish steel industry.

\section{Acknowledgments}

This research was financed by Nordforsk as part of the Nordwit Centre of Excellence.

\section{References}

Abrahamsson, L., Johansson, J. (2006). From grounded skills to sky qualifications: A study of workers creating and recreating qualifications, identity and gender at an underground iron ore mine in Sweden, Journal of Industrial Relations 48(5): 657-676. doi: https://doi. org/10.1177/0022185606070110.

Acker, J. (1990). Hierarchies, Jobs, Bodies: A Theory of Gendered Organization, Gender and Society 4(4): 139-58.

Alvesson, M. (1998). Gender relations and identity at work: A case study of masculinities and femininities in an advertising agency, Human Relations 51(8): 969-1005. doi: https://doi. org/10.1177/001872679805100801.

Amis, J. M., Mair, J., \& Munir, K. A. (2020). The organizational reproduction of inequality, Academy of Management Annals 14(1): 195-230. doi: https://doi.org/10.5465/annals.2017.0033.

\section{다(1) $\Theta$}


Andersson, E., \& Lidestav, G. (2016). Creating alternative spaces and articulating needs: Challenging gendered notions of forestry and forest ownership through women's networks, Forest Policy and Economics 67: 38-44. doi: https://doi.org/10.1016/j.forpol. 2016.03.014.

Andersson, R. (2018). The myth of Sweden's success: A deconstructive reading of the discourses in gender mainstreaming texts, European Journal of Women's Studies 25(4): 455-469. doi: https://doi.org/10.1177/1350506817743531.

Bacchi, Carol (2009). Analysing policy: What's the Problem Represented to be? Frenchs Forest, N.S.W.: Pearson.

Bagilhole, B. M. \& Dainty, A. R. J. \& Neale, R. H. (2002). A woman engineer's experiences of working on British construction sites, International Journal of Engineering Education 18(4): 422-429.

Baublyte, G., Korhonen, J., D’Amato, D., \& Toppinen, A. (2019). 'Being one of the boys': Perspectives from female forest industry leaders on gender diversity and the future of Nordic forest-based bioeconomy, Scandinavian Journal of Forest Research 34(6): 521-528. doi: https://doi.org/10.1080/02827581.2019.1598484.

Carvalho, I., Costa, C., Lykke, N., Torres, A. (2018). Agency, structures and women managers' views of their careers in tourism. Women's Studies International Forum 71:1-11. doi: https://doi.org/10.1016/i.wsif.2018.08.010.

Demaiter, E. I., \& Adams, T. L. (2009). 'I really didn't have any problems with the malefemale thing until.': Successful women's experiences in IT organizations, Canadian Journal of Sociology 34(1): 31-54.

Derks, B., Ellemers, N., van Laar, C., \& de Groot, K. (2011). Do sexist organizational cultures create the queen bee? British Journal of Social Psychology 50(3): 519-535. doi: https://doi.org/10.1348/014466610X525280.

Dwivedi, P., Joshi, A., \& Misangyi, V. F. (2018). Gender-inclusive gatekeeping: How (mostly male) predecessors influence the success of female CEOs, Academy of Management Journal 61(2): 379-404. doi: https://doi.org/10.5465/amj.2015.1238.

Einarsdottir, U. D., Christiansen, T. H., \& Kristjansdottir, E. S. (2018). 'It's a man who runs the show': How women middle-managers experience their professional position, opportunities, and barriers, SAGE Open 8(1): 215824401775398. doi: https://doi.org/ 10.1177/2158244017753989.

Ely, R., \& Padavic, I. (2007). A feminist analysis of organizational research on sex differences, The Academy of Management Review 32(4): 1121-1143. doi: https://doi.org/10.5465/ AMR.2007.26585842.

Faulkner, W. (2009a). Doing gender in engineering work place cultures. I. Observations from the field, Engineering Studies 1(1): 3-18. doi: https://doi.org/10.1080/1937862090 2721322.

Faulkner, W. (2009b). Doing gender in engineering workplace cultures. II. Gender in/authenticity and the in/visibility paradox, Engineering Studies 1(3): 169-189. doi: https://doi. org/10.1080/19378620903225059.

Fletcher, J. K. (1999). Disappearing Acts. Gender, Power, and Relational Practice at Work, Cambridge, Mass.: MIT Press.

Glass, C., \& Cook, A. (2018). Do women leaders promote positive change? Analyzing the effect of gender on business practices and diversity initiatives: Women leaders, Human Resource Management 57(4): 823-837. doi: https://doi.org/10.1002/hrm.21838.

Halford, S. \& Leonard, P. (2001). Gender, Power and Organisations. An Introduction, Basingstoke: Palgrave.

Harman, C., \& Sealy, R. (2017). Opt-in or opt-out: Exploring how women construe their ambition at early career stages, Career Development International 22(4): 372-398. doi: https://doi.org/10.1108/CDI-08-2016-0137. 
Hatmaker, D. M. (2013). Engineering identity: Gender and professional identity negotiation among women engineers, Gender, Work \& Organization 20(4): 382-396. doi: https://doi. org/10.1111/j.1468-0432.2012.00589.x.

Holgersson, C., \& Romani, L. (2020). Tokenism revisited: When organizational culture challenges masculine norms, the experience of token is transformed, European Management Review, doi: https://doi.org/10.1111/emre.12385.

Holt, A. (2010). Using the telephone for narrative interviewing: A research note, Qualitative Research 10(1): 113-121. doi: https://doi.org/10.1177/1468794109348686.

Husu, Liisa (2005). Dold könsdiskriminering på akademiska arenor. Osynligt, synligt, subtilt, Stockholm: Högskoleverket. [Hidden gender discrimination on academic arenas. Invisible, visible, subtle.].

Johansson, M.,\& Ringblom, L. (2017). The business case of gender equality in Swedish forestry and mining - restricting or enabling organizational change, Gender, Work \& Organization 24(6): 628-642. doi: https://doi.org/10.1111/gwao.12187.

Johansson, K., Andersson, E., Johansson, M., \& Lidestav, G. (2019). Conditioned openings and restraints: The meaning-making of women professionals breaking into the male-dominated sector of forestry, Gender, Work \& Organization. doi: https://doi.org/10.1111/gwao.12403.

Joshi, A. (2014). By whom and when is women's expertise recognized? The interactive effects of gender and education in science and engineering teams, Administrative Science Quarterly 59(2): 202-239.

Kanter, R. M. (1977). Men and Women of the Corporation, New York: Basic books.

Kark, R., Waismel-Manor, R., \& Shamir, B. (2012). Does valuing androgyny and femininity lead to a female advantage? the relationship between gender-role, transformational leadership and identification, The Leadership Quarterly 23(3): 620-640. doi: https://doi. org/10.1016/j.leaqua.2011.12.012.

Khilji, S. E., \& Pumroy, K. H. (2019). We are strong and we are resilient: Career experiences of women engineers, Gender, Work \& Organization 26(7): 1032-1052. doi: https://doi. org/10.1111/gwao.12322.

Kvande, E. (1999). In the belly of the beast: Constructing femininities in engineering organizations, European Journal of Women's Studies 6(3): 305-328. doi: https://doi.org/ $10.1177 / 135050689900600304$.

Lewis, P., \& Simpson, R. (2012). Kanter revisited: Gender, power and (in)visibility, International Journal of Management Reviews 14(2): 141-158. doi: https://doi.org/10.1111/ j.1468-2370.2011.00327.x.

Martinsson, L., Griffin, G. \& Giritli Nygren, K. (eds.) (2017). Challenging the Myth of Gender Equality in Sweden, Bristol: Policy Press.

Miller, Gloria E. (2004). Frontier masculinity in the oil industry: The experience of women engineers, Gender, Work and Organization 11(1): 47-73.

Muhr, S. L. (2011). Caught in the gendered machine: On the masculine and feminine in cyborg leadership, Gender, Work \& Organization 18(3): 337-357. doi: https://doi. org/10.1111/j.1468-0432.2010.00529.x.

Powell, A., Bagilhole, B., \& Dainty, A. (2009). How women engineers do and undo gender: Consequences for gender equality, Gender, Work \& Organization 16(4): 411-428. doi: https://doi.org/10.1111/j.1468-0432.2008.00406.x.

Powell, G. N., \& Butterfield, D. A. (2013). Sex, gender, and aspirations to top management: Who's opting out? who's opting in? Journal of Vocational Behavior 82(1): 30-36. doi: https://doi.org/10.1016/j.jvb.2012.11.003.

Reskin, Barbara F. \& McBrier, Debra B. (2000). Why not ascription? Organizations' employment of male and female managers, American Sociological Review 65(2): 210-233.

Ridgeway, C. L., \& Smith-Lovin, L. (1999). The gender system and interaction, Annual Review of Sociology 25(1): 191-216. doi: https://doi.org/10.1146/annurev.soc.25.1.191. 
Rudman, L. A., Moss-Racusin, C. A., Phelan, J. E., \& Nauts, S. (2012). Status incongruity and backlash effects: Defending the gender hierarchy motivates prejudice against female leaders, Journal of Experimental Social Psychology 48(1): 165-179. doi: https://doi. org/10.1016/i.jesp.2011.10.008.

SCB, Statistics Sweden (2019). Allt färre jobbar inom stålindustrin. [Fewer and fewer people work in steel industry]. https://www.scb.se/hitta-statistik/artiklar/2019/allt-farre-jobbar-inom-stalindustrin/ [Accessed April 15, 2020].

Seron, C., Silbey, S., Cech, E., \& Rubineau, B. (2018). 'I am not a feminist, but ...'’ Hegemony of a meritocratic ideology and the limits of critique among women in engineering, Work and Occupations 45(2): 131-167. doi: https://doi.org/10.1177/0730888418759774.

Stanley, L. (1992). The Auto/Biographical I, The Theory and Practice of Feminist Auto/Biography, Manchester: Manchester University Press.

Stenbacka, S., Grubbström, A., Forsberg, G. (2018). Gendered youth strategies for inclusion in a changing society: Breaking or reproducing the local gender contract? Area 50(4): 520-528. doi: https://doi.org/10.1111/area.12392.

Watkins, M. B., Simmons, A., Umphress, E. (2019). It's not black and white: toward a contingency perspective on the consequences of being a token, Academy of Management Perspectives 33(3): 334-365. doi: https://doi.org/10.5465/amp.2015.0154.

Watts, J. H. (2007). Porn, pride and pessimism: Experiences of women working in professional construction roles, Work, Employment \& Society 21(2): 299-316. doi: https://doi. org/10.1177/0950017007076641. 